\title{
Comparative Analysis of Innovative PV Microgrids in Paris and Nice, France
}

\author{
Dr. Aung $\mathrm{Ze} \mathrm{Ya}^{1 *}$
}

\begin{abstract}
:
This present research addresses the mix of the two innovative ideas: the focus on the DC loads for avoiding the conventional conversion losses in the building and the comparative analysis between the innovative Grid-connected PV Microgrid models in two different French Cities, Paris and Nice. The DC load profile of the Office and the proposed models can also demonstrate the enhancement of the sustainability by saving the Energy Consumption and Energy Charges as well as the reduction of GHG Emissions. The modeling and simulation are performed in HOMER Pro (Version 3.6.2). The techno-economic results of the optimistic models are beneficial for the planning and the implementation of PV Microgrid projects at the buildings in nowadays Green Revolution.
\end{abstract}

Key Words: PV Microgrid models, Paris, Nice, HOMER Pro, DC Office

\section{Introduction}

\subsection{PV Applications}

If the $19^{\text {th }}$ century was the age of coal and the $20^{\text {th }}$ of oil, the $21^{\text {st }}$ will be the age of the sun. Solar energy is set to play an ever-increasing role in generating the form, and affecting the appearance and construction, of buildings. The principal reason for this is that photovoltaic (PV) systems which produce electricity directly from solar radiation are becoming more widespread as their advantages become apparent and as costs fall [7].

PV systems have been in operation in France since the 1980s. There are three definitions of PV in France [2]:

- Grid-connected distributed PV power system: electricity-producing system applied to residential, tertiary, commercial, industrial and agricultural buildings, or simply installed in the built environment (power range: $\mathrm{kW}$ to $\mathrm{MW}$ ).

- Grid-connected centralized PV power system: ground-mounted production system that supplies bulk power electric energy (power over $1 \mathrm{MW}$ ).

- Off-grid PV power system: system installed to provide power mainly to a household or village not connected to the utility grid. Can also provide power to a variety of industrial and agricultural applications such as telecommunication relays, water pumping, safety and protection devices, etc. (power range: $\mathrm{kW}$ to several hundred $\mathrm{kW}$ ). French Electric Utility, EDF (Electricity of France) specializes in electricity, from engineering to distribution. Its electricity network is composed of RTE (Transport System of Electricity) and ErDF (Electricity Network Distribution) [5]. 
Table 1 mentions the cumulative installed PV power in three sub-markets during 20052014 (MW) in France [2]. It is evident that the capacity of the Grid-connected distributed application is larger than Grid-connected centralized ground-mounted and Off-grid. Therefore, PV Microgrid models for Grid-connected distributed application are proposed at the Section 2 of the present research.

Table 1. Cumulative installed PV power in three sub-markets, 2005-2014 (MW)

\begin{tabular}{|l|l|l|l|l|l|l|l|l|l|l|}
\hline Application & 2005 & 2006 & 2007 & 2008 & 2009 & 2010 & 2011 & 2012 & 2013 & 2014 \\
\hline Off-grid & 20 & 21.5 & 22.5 & 22.9 & 29.2 & 29.3 & 29.4 & 29.6 & 29.7 & 29.75 \\
\hline $\begin{array}{l}\text { Grid-connected } \\
\text { centralized } \\
\text { ground-mounted }\end{array}$ & 0 & 0 & 0 & 7 & 42 & 242 & 702 & 1022 & 1342 & 1680 \\
\hline $\begin{array}{l}\text { Grid-connected } \\
\text { distributed }\end{array}$ & 5.9 & 15.3 & 49 & 83 & 299 & 936 & 2236 & 3035 & 3367 & 3968 \\
\hline $\begin{array}{l}\text { Grid-connected } \\
\text { sub-total }\end{array}$ & 5.9 & 15.3 & 49 & 90 & 341 & 1178 & 2938 & 4057 & 4709 & 5648 \\
\hline Total (MW) & 25.9 & 36.8 & 71.5 & 11.3 & 370 & 1207 & 2967 & 4087 & 4739 & 5678 \\
\hline
\end{tabular}

Source: SOeS, previous IE A NSR reports for France. A few figures from previous IE A NSR reports have been reviewed to take into account the latest adjustments from SOeS, PV Atlas Observ'ER and ADEME.

\subsection{Energy Efficiency and its Challenge}

UN 2030 Agenda adopts a set of 17 Sustainable Development Goals (SDGs). Goal 7 is ensure access to affordable, reliable, sustainable, and modern energy for all. In it, 7.2 is to increase substantially the share of Renewable Energy in the global energy mix and 7.3 is to double the global rate of improvement in Energy Efficiency by 2030 [3]. The directive 2012/27/EU on Energy Efficiency (EED) establishes a common framework of measures for the promotion of Energy Efficiency. This contributes to reaching the 20\% target on EU Energy Efficiency by 2020 and paves the way for further improvements beyond that date. France has set itself two objectives, pursuant to article 3 of Directive 2012/27/EU on Energy Efficiency (EED), to reduce its final energy consumption to 131.4 Mtep (Million-Ton Equivalent of Petroleum) and its primary energy consumption to 236.3 Mtep in 2020. The building sector, representing $44.5 \%$ of France's final energy consumption in 2012, constitutes a major challenge for Energy Efficiency policies [4].

One of the roots of the power losses in the buildings is the unharmonious systems between the power supply and applications. The building power supply is the conventional AC system. However, DC is the essential power usage for nowadays electronics appliances (TV, computer, etc) as well as LED. That aspect is significant in the battery based digital appliances of Globalization age such as laptop, tablet, mobile phone, electric shaver, etc. Thus, it is essentially needed to use the AC to DC converters for each appliance. As a undesirable result, there are converter power losses for every appliance. Then, the total hidden power losses per year for the whole building may be certainly large. Then, the combined power losses per year for the whole City and the whole country are obviously larger.

Photovoltaic (PV) is the most commonly use in building. However, PV's inherent output DC is needed to convert AC for the conventional building supply. Again, AC is 
converted to DC for use in demand side. Then, there are step-by-step multistage converter losses from the PV supply side to the DC demand side as illustrated in Fig. 1. For more clear view, the other portions (Grid, metering and protections) are omitted in that Fig. The characteristics of the various types of loads with respect to AC to DC conversion is studied in [6] as the conversion efficiencies are lower (20\%) for lower power devices and higher for high power devices.

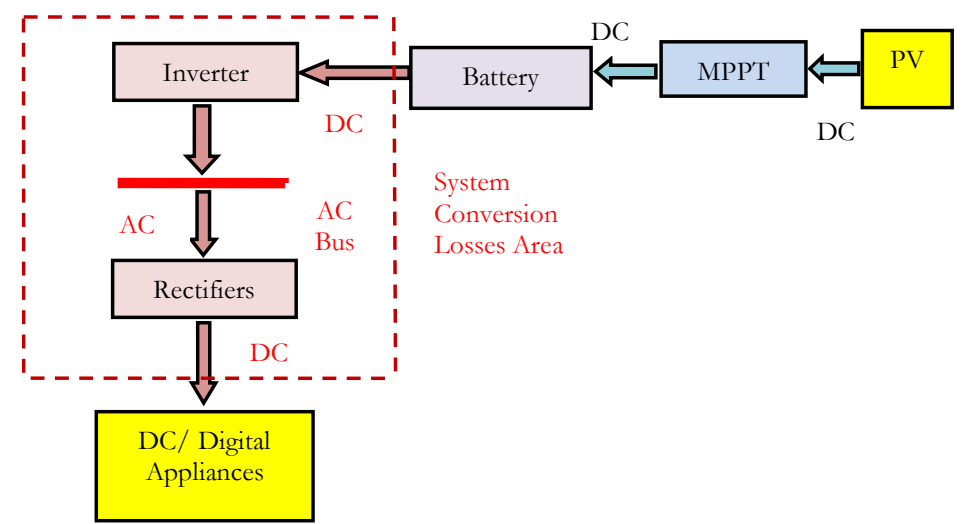

Fig.1 Conversion Losses Area of Conventional AC Bus and PV Systems

\section{Proposed PV Microgrid Models in HOMER Pro}

\subsection{Proposed Grid-connected PV Model}

For both Cities, the same Grid-connected PV Microgrids are modeled in the HOMER Pro (Version 3.6.2) as depicted in Fig. 2. The hybrid coupled AC-DC bus architecture of the conventional system and the proposed system is the same. However, the innovative idea of the proposed system is the considered DC loads are directly supplied from the DC bus to avoid the AC-DC conversion losses for each load.

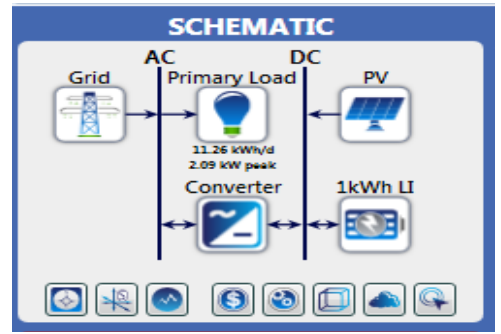

(a)

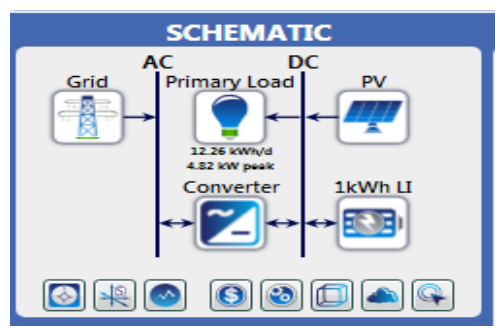

(b)

Fig.2 Grid-connected PV Model in HOMER Pro: (a) Conventional System; (b) Proposed System

\subsection{Two Locations and Solar PV Potentials}

GHI is the most important parameter for calculation of PV electricity yield. GHI is the sum of Direct Horizontal Irradiation (DHI) and Diffuse Horizontal Irradiation (DIF) [9]. As highlighted in Fig. 3. GHI of French southern part is obviously larger than French northern part. 


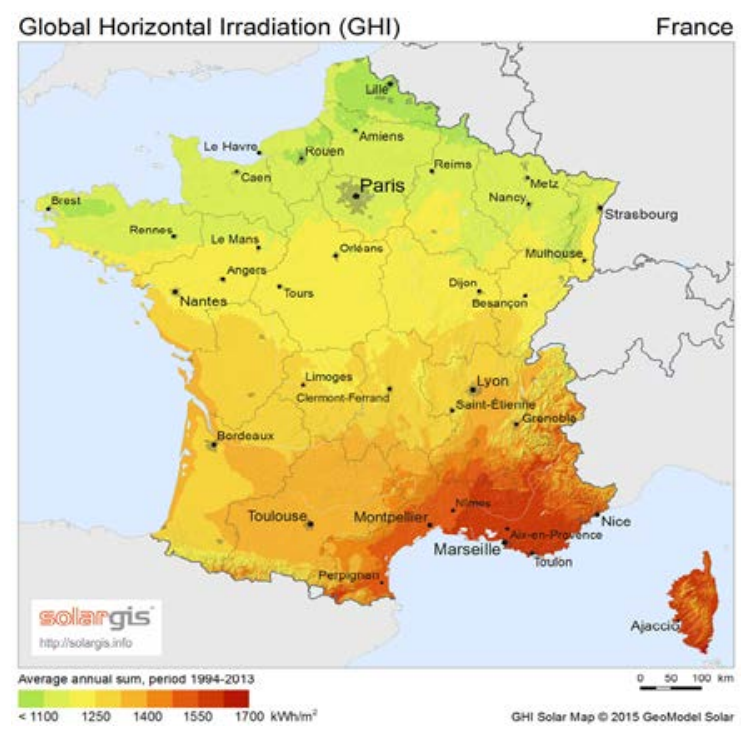

Fig.3 French Solar Potential Map

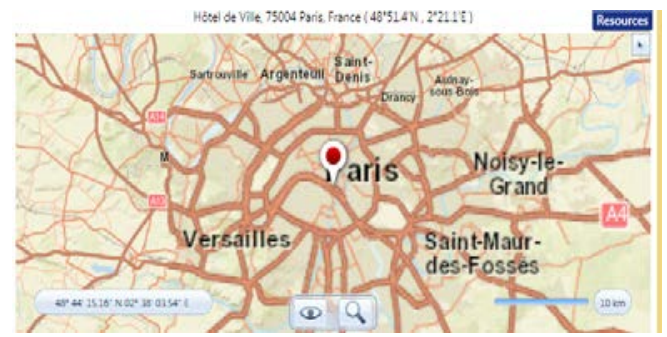

(a)

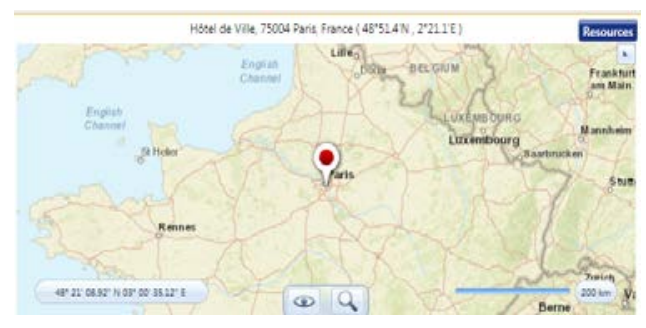

(b)

Fig.4 Location of Paris City in HOMER Pro: (a) By Region; (b) By State

The proposed two models are considered at the Paris and Nice Cities to know the different technological design aspects, ecological factors as well as economic results that impacted from different locations and PV radiations. Time is set as (UTC+01:00) Brussels, Copenhagen, Madrid, Paris. The maps of Paris and Nice Cities in HOMER Pro platform are reported in Fig. 4 and Fig. 5.

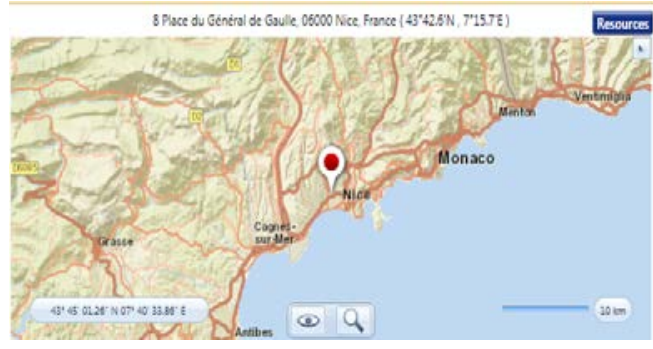

(a)

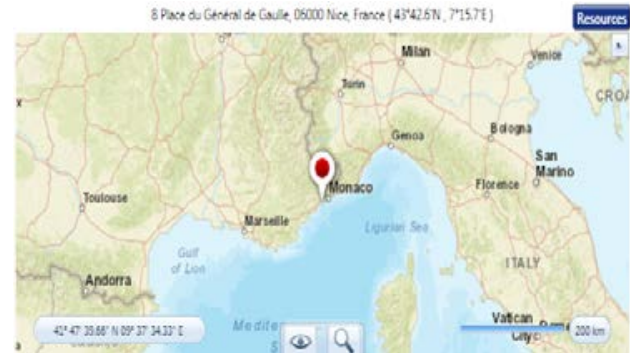

(b)

Fig.5 Location of Nice City in HOMER Pro: (a) By Region; (b) By State 
Solar GHI data of Paris and Nice in 2015 are exported from [10]. Based on that data, it is observed that Solar GHI of Nice is higher than Solar GHI of Paris corresponding with the Fig. 3. Then, these data are inputted into HOMER Pro. The Scaled Annual Average of Paris and Nice are $3.44 \mathrm{kWh} / \mathrm{m}^{2} /$ day and $4.55 \mathrm{kWh} / \mathrm{m}^{2} /$ day respectively. Solar GHIs and Hourly Global Solar in HOMER Pro for both Cities are shown in Fig. 6 and Fig. 7.

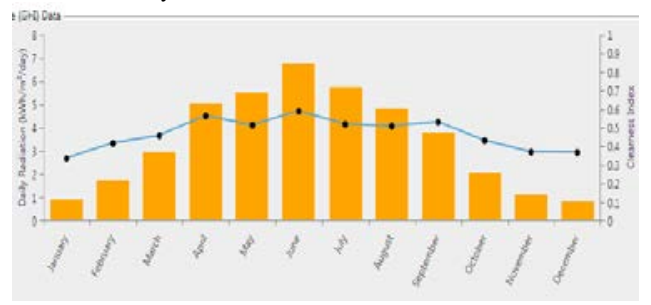

(a)

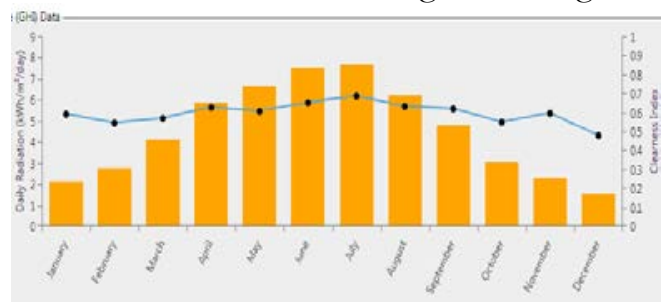

(b)

Fig.6 Solar GHI (kWh/m²/day) in HOMER Pro: (a) Paris City; (b) Nice City

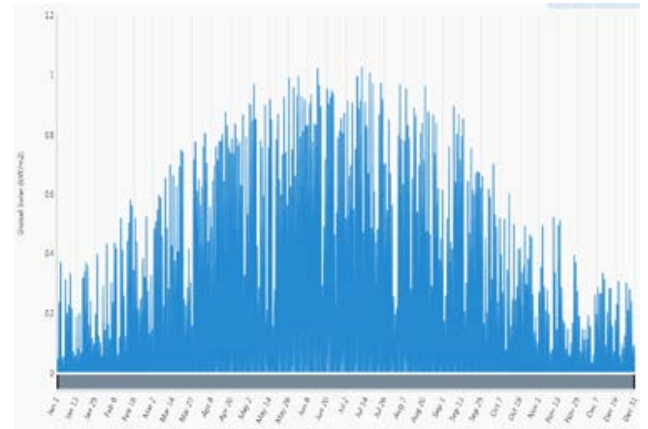

(a)

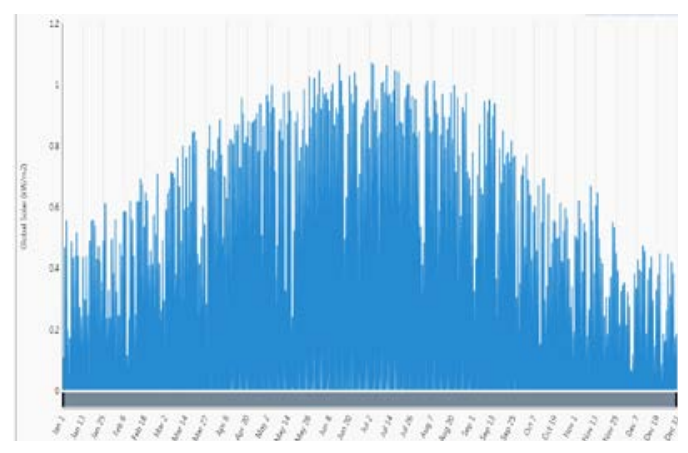

(b)

Fig.7 Hourly Global Solar (kW/ $\left.\mathrm{m}^{2}\right)$ in HOMER Pro: (a) Paris City; (b) Nice City

\subsection{Modeling Parameters of the Project}

\section{(A) Economics and Constraints}

France is $100 \%$ electrified with reliable power system. Therefore, Maximum annual capacity shortage is set as $0 \%$. In this study, Solar is only modeled. Then, in the percentage of renewable output, Solar power output is inputted as $100 \%$. Renewable Fraction is inputted as $80 \%$ and $100 \%$ for Sensitivity Values as shown in Fig. 8.

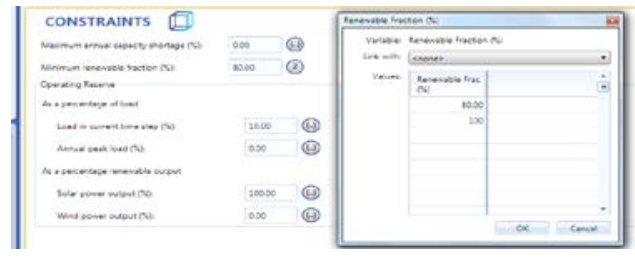

Fig.8 Constraints Inputs in HOMER Pro

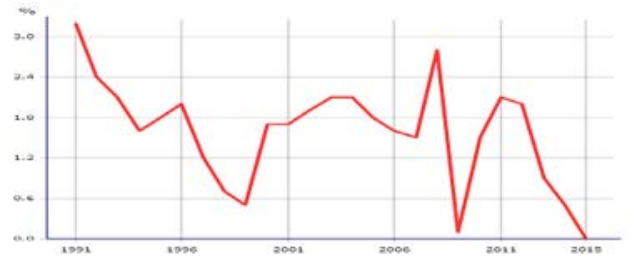

Fig.9 Inflation Rate in France (\%)

Source: Insee, consumer price indices

Nominal discount rate is 0.75 [11]. Expected inflation rate is 0 as highlighted in Fig. 9 [12]. The project lifetime is 20 years [13]. France is the member state country of EU. Then, Currency is set as Euro (€) in HOMER Pro supportive tool. 


\section{(B) Grid Parameters}

There are three options for electricity tariffs in France: Base, Heures Creuses and Tempo [14, 15]. If your water and space heating is not electric then you would be best to choose the Base tariff $(0.1372 € / \mathrm{kWh})$, which has the same rate throughout the day and year.

If you have a night-storage electric water heater, or storage radiators, then you would be best advised to choose Heures Creuses option $(0.151 € / \mathrm{kWh})$, which provides off peak electricity rates $(0.1044 € / \mathrm{kWh})$ to heat your appliances. EDF also offer Tempo with charges that vary according to the time of year and of day. [14].

In this study, the water and space heating are not included in the load profile. Therefore, tariff (Grid Power Price) is $0.1372 € / \mathrm{kWh}$ [15] and Feed-in-tariff is $0.1327 € / \mathrm{kWh}$ [8]. In addition, Grid Emissions are set as: Carbon Dioxide $79 \mathrm{~g} / \mathrm{kWh}$, Sulphur Dioxide 0.05 $\mathrm{g} / \mathrm{kWh}$ and Nitrogen Oxide $0.07 \mathrm{~g} / \mathrm{kWh}[16,17,18]$.

\section{(C) Components of PV Power System}

In France, $90 \%$ of installed PV modules are based on crystalline silicon and $10 \%$ are thin films (essentially cadmium telluride for ground-mounted power plants) [2]. Therefore, the mono-crystalline type module is selected. Its specifications are $20.3 \%$ efficiency, Temperature coefficient $0.0013963 /{ }^{\circ} \mathrm{C}$ and NOCT (Normal Operating Cell Temperature) $45 \pm 2{ }^{\circ} \mathrm{C}$. That NOCT is also the Sensitivity values.

The cost inputs of the PV for $1 \mathrm{~kW}$ are Capital cost $1100 €$, Replacement cost 0 and Operation \& Maintenance cost $70 €$. The considered sizes $(\mathrm{kW})$ for PV are 1, 5, 10, 15, $20,25,30$ and 35 .

The maximum power point tracking (MPPT) converter continuously changes the operating point due to changes in solar irradiance, load and tracks the maximum power point. In this study, its inputs for $1 \mathrm{~kW}$ are set as: Capital cost $500 €$, Replacement cost $450 €$ and Operation \& Maintenance cost $45 €$. The search space for MPPT is 1, 5, 10, 12,15 and 20.

The Bi-directional Converter is inputted as $1.5 \mathrm{~kW}$ for Capital cost $600 €$, Replacement cost $500 €$ and Operation \& Maintenance cost $70 €$. The considered sizes $(\mathrm{kW})$ are 1.5, 3, $6,9,12,15$ and 20 . Its lifetime is 15 years, the inverter efficiency is $90 \%$ and the rectifier efficiency is $85 \%$.

The battery is set as $1 \mathrm{kWh}$ Lithium-ion battery. Its costs are Capital cost $600 €$, Replacement cost $500 €$ and Operation \& Maintenance cost $100 €$. The considered sizes $(\mathrm{kW})$ for battery are 1, 3, 5, 7, 9 and 10. Its specifications are $6 \mathrm{~V}, 166.667$ Ah capacity, 90\% roundtrip efficiency, Maximum charge current 166.667 A, Maximum Discharge current $500 \mathrm{~A}$, lifetime 15 years and throughput is $3000 \mathrm{kWh}$.

\subsection{Load Profile and Savings}

In this study, the target of the considered loads is towards the least conversion losses. Then, the loads are selected for inherently DC as desktop computers (PCs), laptops, printers, LED lights, Security System and Wi-fi Routers. Thus, the tentative building is regarded as the Office. The DC loads and profile that set into HOMER Pro is reflected in Fig. 10 and Fig. 11. 


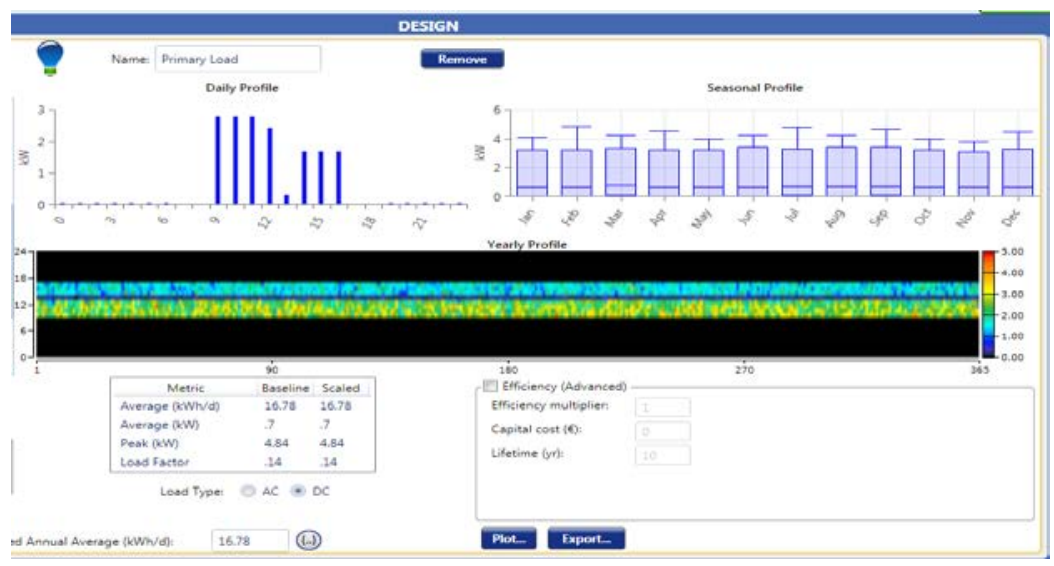

Fig.10 DC Primary Load Inputs in HOMER Pro

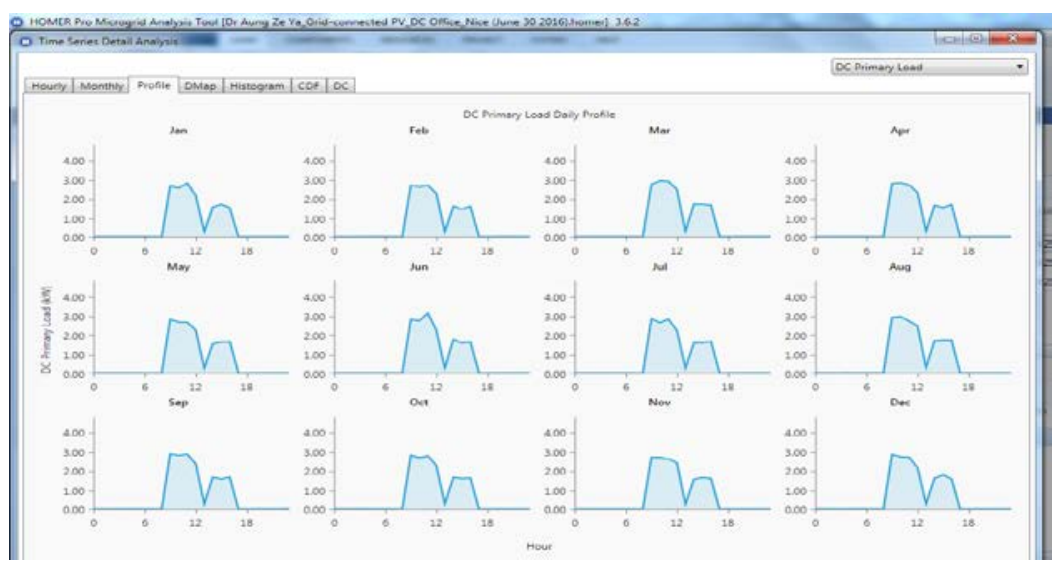

Fig.11 DC Primary Load Profile in HOMER Pro

Computers and related equipments as well as rechargeable electronics equipments can be saved $20 \%$ power by avoiding AC-DC conversion process. In addition, the LED lighting can save $20 \%$ and the security system can save $17 \%$ conversion losses [6]. Then, the DC loads and saving matrix that including the Energy Saving, Electricity Charges Saving and Greenhouse Gas Emissions Reduction that will be outcome from avoiding AC-DC Conversion Losses is listed in Table 2.

Table 2. Loads and Saving Matrix

\begin{tabular}{|l|l|l|l|l|}
\hline Load & $\begin{array}{l}\text { Energy } \\
\text { Saving } \\
(\mathrm{kWh} / \text { day })\end{array}$ & $\begin{array}{l}\text { Energy } \\
\text { Saving } \\
(\mathrm{kWh} / \text { week })\end{array}$ & $\begin{array}{l}\text { Energy } \\
\text { Saving } \\
(\mathrm{kWh} / \mathrm{yr})\end{array}$ & $\begin{array}{l}\text { Electricity } \\
\text { Charges Saving } \\
(€ / \mathrm{yr})\end{array}$ \\
\hline PCs & 1.554 & 7.770 & 388.500 & 53.302 \\
\hline Laptops & 1.328 & 6.640 & 332.000 & 45.550 \\
\hline LED Lightings & 0.350 & 1.750 & 87.500 & 12.005 \\
\hline $\begin{array}{l}\text { Security System } \\
\text { \& Wi-fi Routers }\end{array}$ & 0.387 & 1.935 & 96.750 & 13.303 \\
\hline Total & 3.619 & 18.095 & 904.750 & 124.160 \\
\hline
\end{tabular}




\section{Simulative Results and Comparative Analysis}

After finishing the simulation in HOMER Pro (Version 3.6.2), the optimum PV Microgrid models for DC Office in Paris and Nice Cities are displayed. There are observed that the same results as well as the different results. The results are comparatively analyzed as the following sub-section headings.

\subsection{Tabular Results}

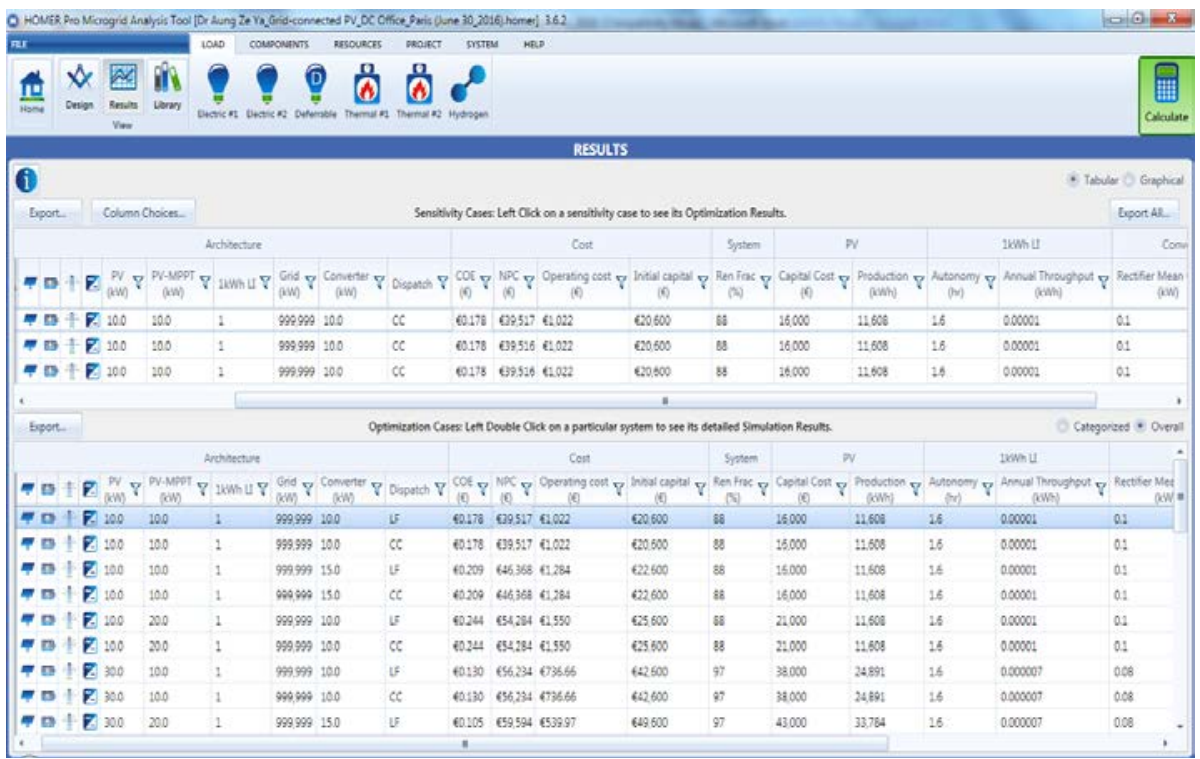

Fig. 12 Simulated Tabular Results of Sensitivity and Optimization Cases for Paris City

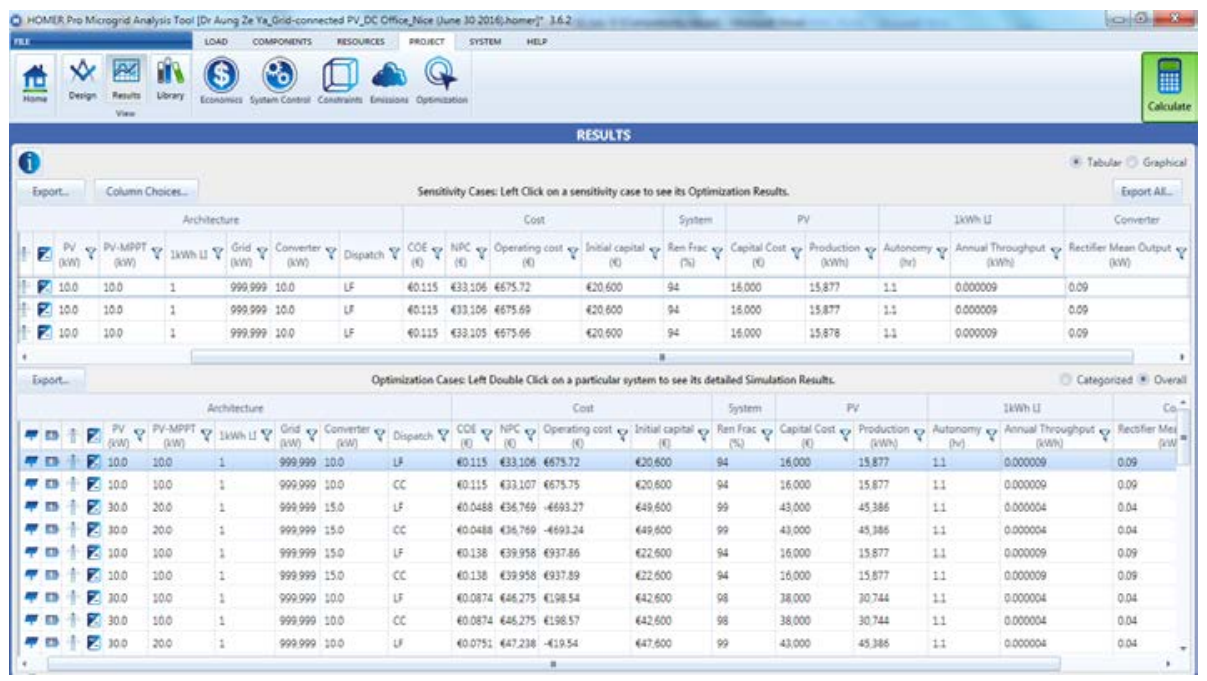

Fig. 13 Simulated Tabular Results of Sensitivity and Optimization Cases for Nice City 
Fig. 12 and Fig. 13 demonstrate the tabular results of HOMER Pro for Paris and Nice Cities. The upper part is mentioned for Sensitivity Cases and the lower part is displayed for Optimization Cases. The displayed results are listed for PV Microgrid models from top to bottom of the optimistic to least cost-effective. The results are categorized with the column headings as the architecture, cost, system, PV, Battery, Converter and Grid. There are no different results on architecture and Initial Capital Cost $(20600 €)$ for both Cities because of the same inputs that mentioned in Section 2.

\subsection{Renewable Fraction}

The difference on Renewable Fraction results is predicted as $88 \%$ for Paris City and $94 \%$ for Nice City. It is notable that these different results are due to the different locations and Solar PV potentials. The different results of the two Cities are more obvious in the Graphical Optimization Surface Plots of HOMER Pro Microgrid Analysis tool as reflected in Fig. 14 and Fig. 15.

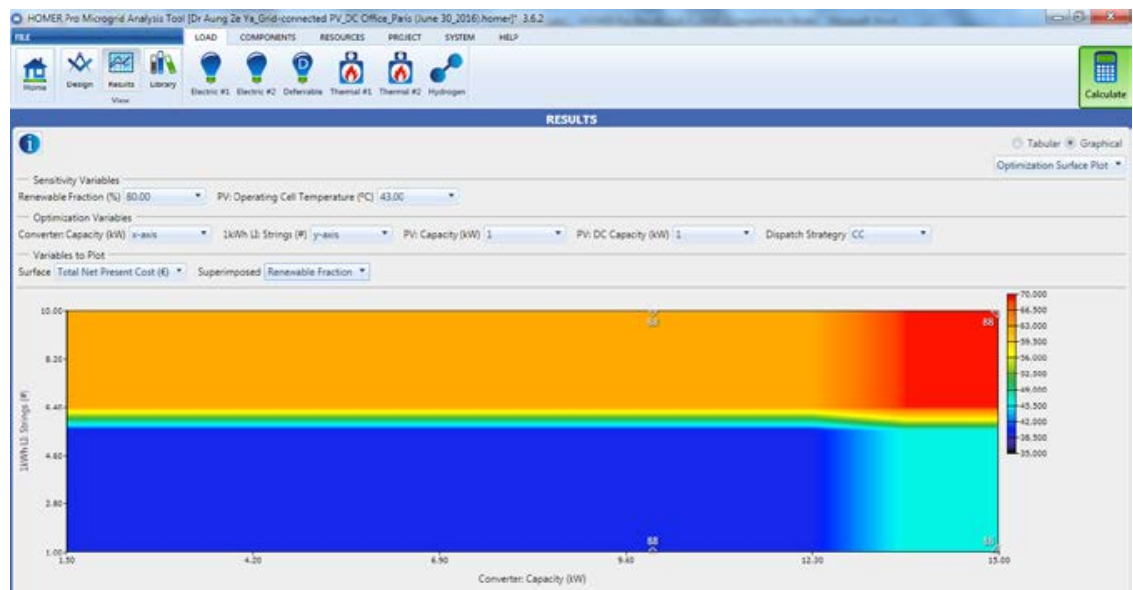

Fig. 14 Simulated Results of Optimization Surface Plot for Paris City

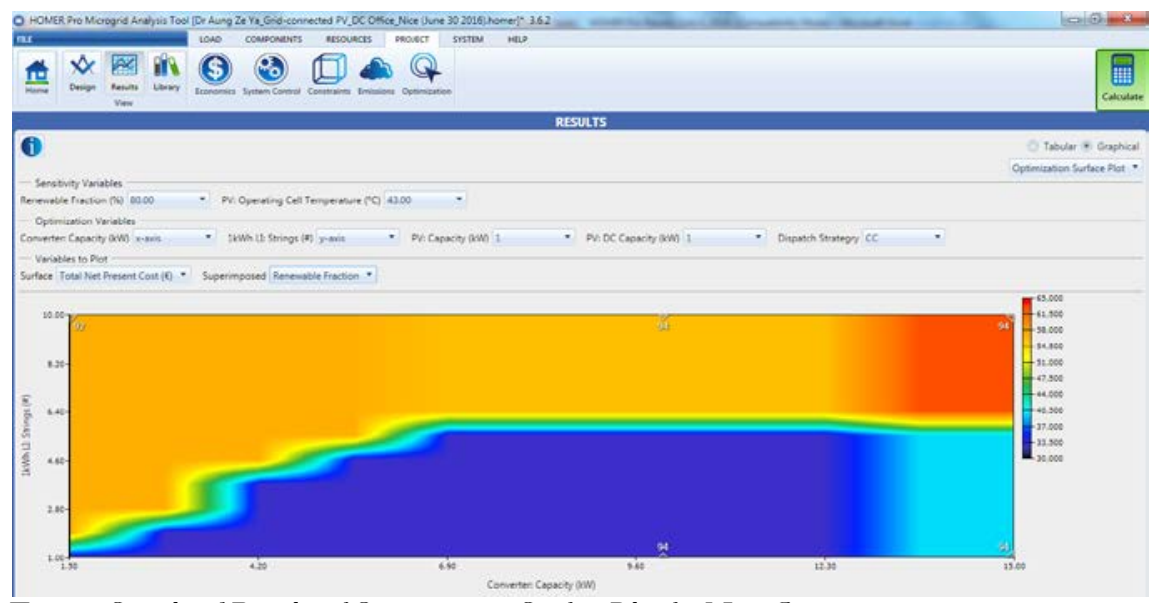

Fig. 15 Simulated Results of Optimization Surface Plot for Nice City 


\subsection{Grid Results}

The monthly scenarios of the Grid are highlighted in Fig. 16 and Fig. 17. From those Figs, it can be easily observed that the figures of monthly Energy Purchased (kWh) for Paris City are greater than the figures of Nice City. On the other hand, the figures of Energy Sold (kWh) and Net Energy Purchased $(\mathrm{kWh})$ of the Nice City are greater than the figures of the Paris City. However, Total Net Present Cost (NPC), Levelized Cost of Energy (COE) and Operating Cost of Paris City are expensive with respect to the Costs of Nice City.

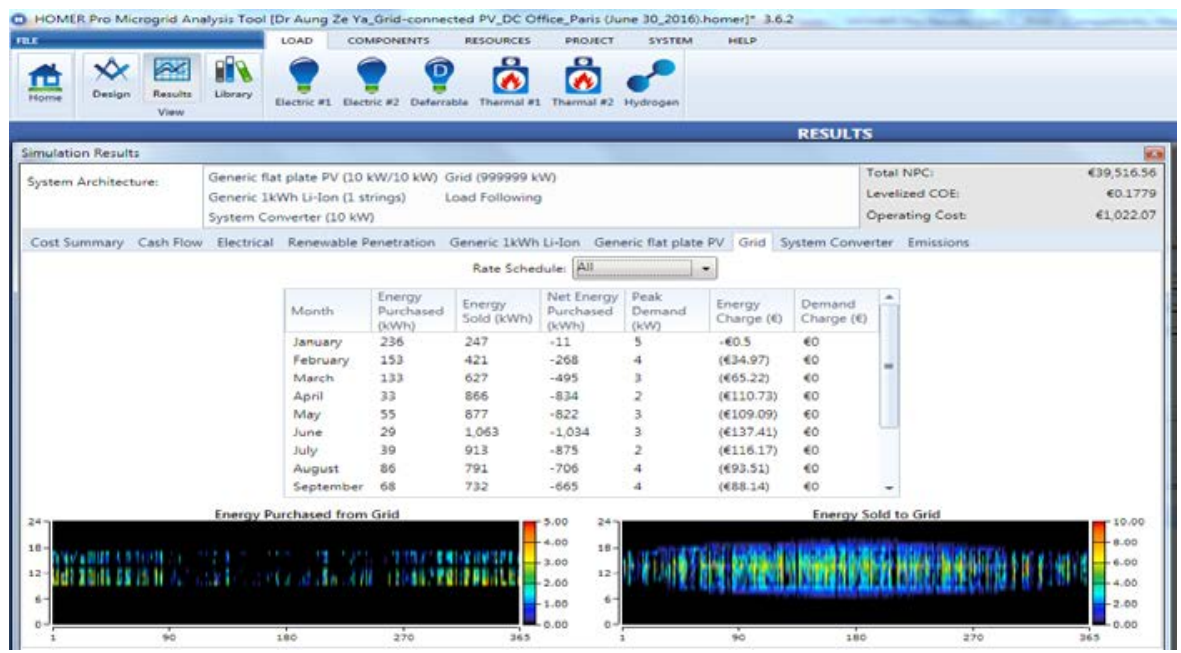

Fig. 16 Grid Results of PV Microgrid Project for Paris City

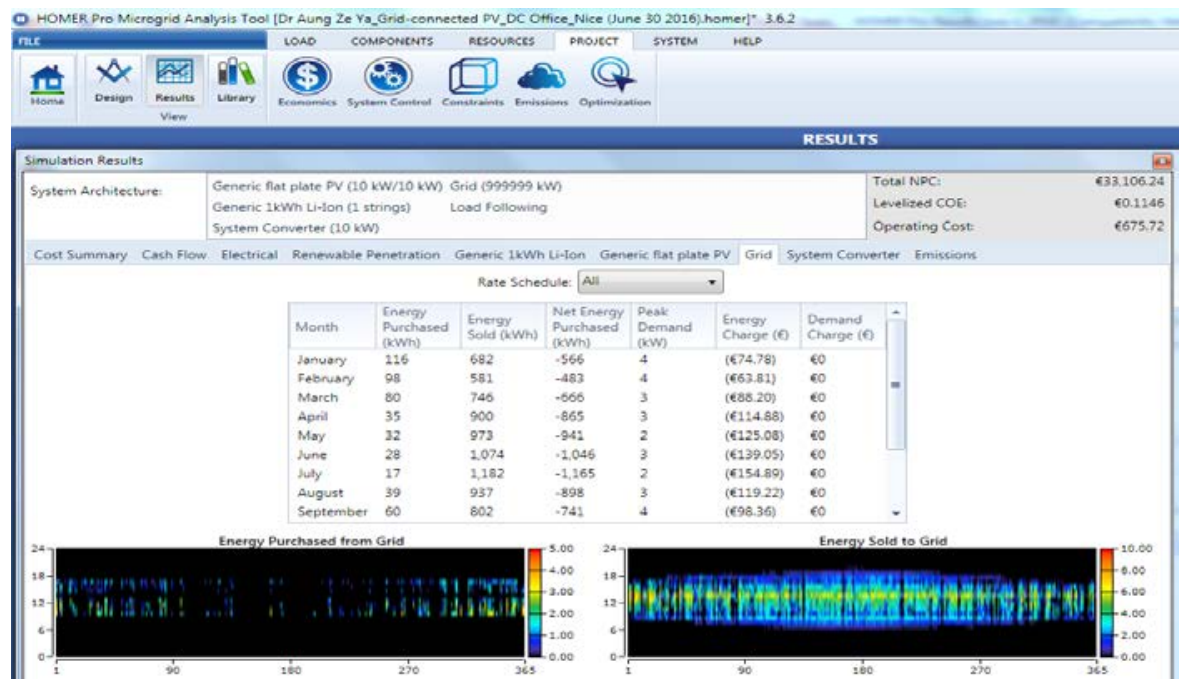

Fig. 17 Grid Results of PV Microgrid Project for Nice City 


\subsection{Electrical and Emissions Results}

Electrical Results of the PV Microgrid projects of the Cities are easily seen in Fig. 18 and Fig. 19. Regarding Overall Grid Purchases Energy, the figure of Paris City $(1447 \mathrm{kWh} / \mathrm{yr})$ is greater than the figure of Nice City $(932 \mathrm{kWh} / \mathrm{yr})$. Meanwhile, Grid Sales Energy of Nice City $(9489 \mathrm{kWh} / \mathrm{yr})$ is larger than Grid Sales Energy of Paris City $(7527 \mathrm{kWh} / \mathrm{yr})$. In Fig. 20, the negative emissions results reflect the emissions reductions. The reductions of Nice project is greater than the Paris project.

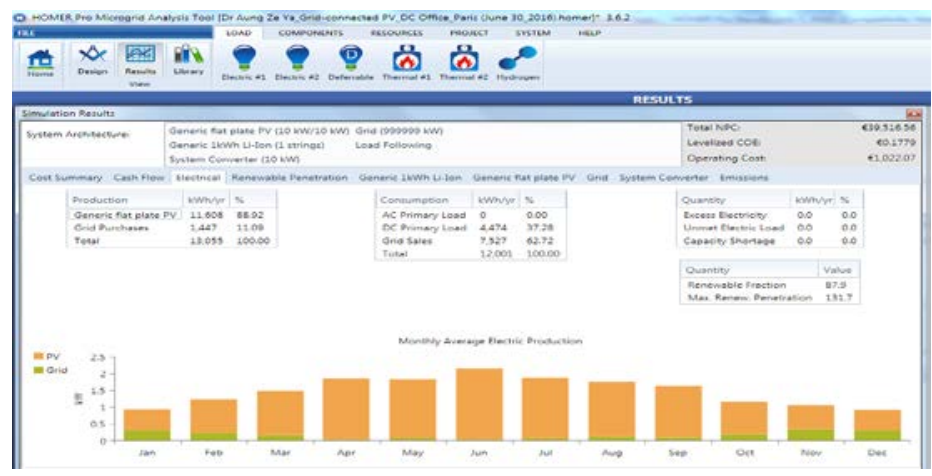

Fig. 18 Electrical Results of PV Microgrid Project for Paris City

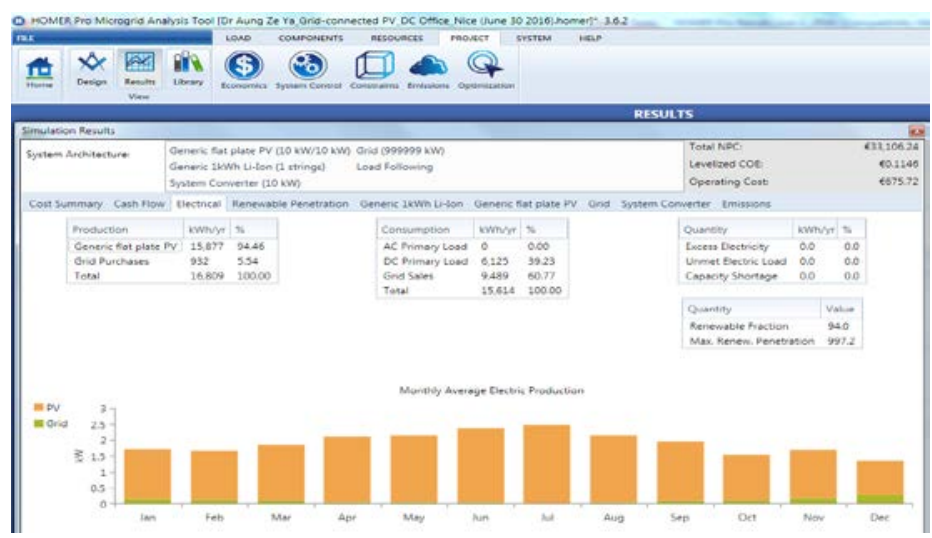

Fig. 19 Electrical Results of PV Microgrid Project for Nice City

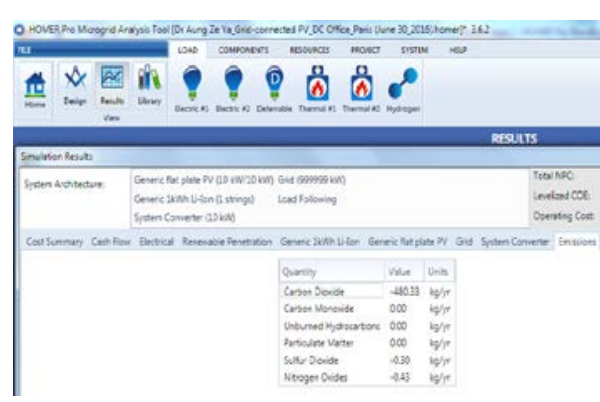

(a)

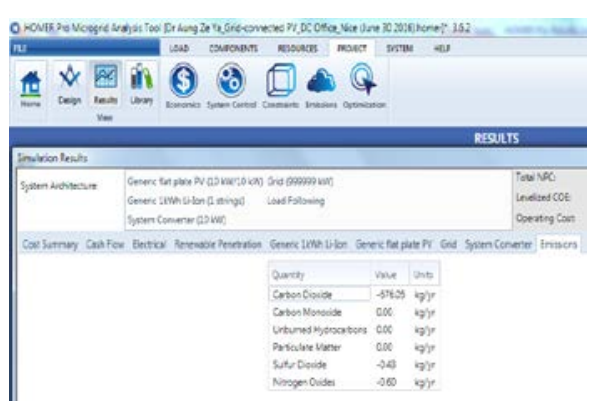

(b)

Fig. 20 Emissions Results: (a) Paris City; (b) Nice City 


\subsection{Overall Comparison}

Table 3 is listed for more evident comparison between the results of PV Microgrid Projects in Paris City and Nice City. The data of saving from avoiding AC-DC Conversion losses are taken from Sub-section 2.4. Nice City enriches the greater Solar Potential than Paris City. As the results, although the same costs are set, COE, NPC and Operating Cost of Nice City are cheaper than the Paris City. Moreover, due to the simulative results from HOMER Pro, Nice City has the greater figures of Renewable Fraction (\%), PV Production (kWh/yr) and Capacity Factor, Net Energy Sole to Grid and Emissions Reductions than Paris City.

Table 3. Results Comparison Matrix

\begin{tabular}{|c|c|c|c|c|c|}
\hline \multicolumn{2}{|l|}{ Description } & \multirow{3}{*}{$\begin{array}{l}\text { Unit } \\
\mathrm{kW}\end{array}$} & \multicolumn{2}{|l|}{ City } & \multirow{3}{*}{$\begin{array}{l}\text { Difference } \\
-\end{array}$} \\
\hline & & & \multirow{2}{*}{$\begin{array}{l}\text { Paris } \\
10\end{array}$} & \multirow{2}{*}{$\begin{array}{l}\text { Nice } \\
10\end{array}$} & \\
\hline Architecture & PV & & & & \\
\hline & PV-MPPT & $\mathrm{kW}$ & 10 & 10 & - \\
\hline & Lithium-Ion Battery & $\mathrm{kWh}$ & 1 & 1 & - \\
\hline & Converter & $\mathrm{kW}$ & 10 & 10 & - \\
\hline & Grid & $\mathrm{kW}$ & 999,999 & 999,999 & - \\
\hline \multirow[t]{4}{*}{ Cost } & $\mathrm{COE}$ & $€ / \mathrm{kWh}$ & 0.178 & 0.115 & 0.063 \\
\hline & NPC & $€$ & 39517 & 33106 & 6411 \\
\hline & Operating Cost & $€$ & 1022 & 675.72 & 346.28 \\
\hline & Initial Capital Cost & $€$ & 20600 & 20600 & - \\
\hline \multicolumn{2}{|c|}{ Average Solar GHI } & $\mathrm{kWh} / \mathrm{m}^{2} /$ day & 3.44 & 4.55 & 1.11 \\
\hline \multicolumn{2}{|c|}{ Renewable Fraction } & $\%$ & 88 & 94 & 6 \\
\hline \multirow[t]{4}{*}{ PV } & Mean Output & $\mathrm{kW}$ & 1.33 & 1.80 & 0.47 \\
\hline & Mean Output & $\mathrm{kWh} / \mathrm{day}$ & 31.80 & 43.50 & 11.7 \\
\hline & Production & $\mathrm{kWh} / \mathrm{yr}$ & 11608 & 15877 & 4269 \\
\hline & Capacity Factor & $\%$ & 13.25 & 18.12 & 4.87 \\
\hline \multirow[t]{2}{*}{ Converter } & Inverter Mean Output & $\mathrm{kW}$ & 0.9 & 1 & 0.1 \\
\hline & Rectifier Mean Output & $\mathrm{kW}$ & 0.1 & 0.09 & 0.01 \\
\hline \multirow[t]{4}{*}{ Grid } & Purchases Energy & $\mathrm{kWh} / \mathrm{yr}$ & 1447 & 932 & 515 \\
\hline & Sales Energy & $\mathrm{kWh} / \mathrm{yr}$ & 7527 & 9489 & 1962 \\
\hline & Net Energy Sole & $\mathrm{kWh} / \mathrm{yr}$ & 6080 & 8557 & 2477 \\
\hline & Profit from Net Energy Sole & $€ / \mathrm{yr}$ & 806.82 & 1135.51 & 328.69 \\
\hline \multirow{3}{*}{$\begin{array}{l}\text { Emissions } \\
\text { Reductions } \\
\text { from PV } \\
\text { Microgrid }\end{array}$} & Carbon Dioxide & $\mathrm{kg} / \mathrm{yr}$ & 480.33 & 676.05 & 195.72 \\
\hline & Sulfur Dioxide & $\mathrm{kg} / \mathrm{yr}$ & 0.30 & 0.43 & 0.13 \\
\hline & Nitrogen Dioxide & $\mathrm{kg} / \mathrm{yr}$ & 0.43 & 0.60 & 0.17 \\
\hline \multirow{3}{*}{$\begin{array}{l}\text { Emissions } \\
\text { Reductions } \\
\text { from } \\
\text { avoiding } \\
\text { AC-DC } \\
\text { Conversion }\end{array}$} & Carbon Dioxide & $\mathrm{kg} / \mathrm{yr}$ & 71.48 & 71.48 & - \\
\hline & Sulfur Dioxide & $\mathrm{kg} / \mathrm{yr}$ & 0.05 & 0.05 & - \\
\hline & Nitrogen Dioxide & $\mathrm{kg} / \mathrm{yr}$ & 0.06 & 0.06 & - \\
\hline \multirow{3}{*}{$\begin{array}{l}\text { Total } \\
\text { Emissions } \\
\text { Reductions }\end{array}$} & Carbon Dioxide & $\mathrm{kg} / \mathrm{yr}$ & 551.81 & 747.53 & 195.72 \\
\hline & Sulfur Dioxide & $\mathrm{kg} / \mathrm{yr}$ & 0.35 & 0.48 & 0.13 \\
\hline & Nitrogen Dioxide & $\mathrm{kg} / \mathrm{yr}$ & 0.49 & 0.66 & 0.17 \\
\hline
\end{tabular}




\section{Conclusions}

This research work investigates the benefits that will be gained from avoiding the AC-DC conversion losses and the impacts of different locations and Solar PV potentials on the design parameters of PV Microgrid models.

Except the inputs of the different locations and Solar potentials, the other inputs in HOMER Pro (Version 3.6.2) platform for the two Cities, Paris and Nice are the same. Then, the same architecture system and the equal initial capital cost are obtained. However, most of the other results, especially in Renewable Fraction, PV Production, Net Energy Sole to Grid and Reductions of $\mathrm{CO}_{2}$ Emissions are predicted as the significantly greater figures for PV Microgrid models in Nice City.

According to the simulative results, it is obvious that the less Solar PV potential can cause the more costs (COE, NPC and Operating Capital). In addition, the more Ecological and Economical benefits are gained from the more blessed Solar Potential. Therefore, in general, it can be regarded as the Solar PV potential is inversely proportional with the operating costs and directly proportional with the benefits.

The innovative ideas and the evidence of this research work could be effectively instrumental for implementation of Positive and Zero-Energy Buildings in Smart Grid as well as Smart Community for Sustainable Future.

\section{Acknowledgements}

First of all, the author offers the deepest acknowledges to his father, U Sein Hla (Author, Accountant in Charge and CEC member of Myanmar Writers Association, Ret. Executive Engineer) and his mother, Daw Htway Lay for their infinite encouragements.

The author reports his respectable gratitude to U Kyaw Zwa Soe (Permanent Secretary, Director General of Department of Technology Promotion and Cooperation, Ministry of Education, Myanmar) for his kind instruction. The author also reports his respectable gratitude to U Tin Wai (Deputy Permanent Secretary, Ministry of Education, Myanmar) for his kind permission. The author is also very grateful to Dr. Myint Thein (Rector of Mandalay Technological University, Myanmar) for his kind instruction.

In addition, the author offers his deep gratitude to Dr. Srdjan Redzepagic (Professor of Economics, ISEM, UNS, France) for his kind support.

The author mentions his thanks to Prof. Dr. Cécile Belleudy (LEAT, University of Nice-Sophia Antipolis, Nice, France), Prof. Dr. Francine Diener (EMMA Coordinator, UNS, France) and Ms. Julie Guillaumat (Project Manager of EMMA, UNS, France) for their valuable supports throughout EMMA Project.

Especially, the author is deeply grateful to Prof. Dr. Jose Carlos Tiago de Oliveira (UNESCO Chair on Intangible Heritage Collaborator, EMMA WEST Coordinator, Center of Philosophy of Sciences, Department of Mathematics, University of Evora, Portugal) for sharing his invaluable experiences and impressive advices.

Moreover, the author mentions special acknowledges to Dr. Peter Lilienthal (CEO of HOMER Energy, USA) for his excellent guidance and support. 
The author presents sincere appreciations to Prof. Dr. Prince G. Gadama (2nd Vice Chancellor, Board of Directors, Cypress International Institute, Texas, USA) for his kind support.

The last but not least, the author offers the heartfelt thanks to his family for their valuable encouragements.

\section{References}

[1] http://www.homerenergy.com

[2] French Environment and Energy Management Agency (ADEME), 2015. Photovoltaic Power Applications in France. National Survey Report 2014 for IEA PVPS, France.

[3] ICSU, ISSC (2015): Review of the Targets for Sustainable Development Goals: The Science Perspective. Paris: International Council for Science (ICSU).

[4] Ministry of Ecology, Sustainable Development and Energy, 2015. National Energy Efficiency Action Plan - 2014, Paris, France.

[5] https://en.wikipedia.org/wiki/\%C3\%89lectricit $\%$ C3\%A9 de France

[6] Garbesi, K. et al., 2011. Catalog of DC Appliances and Power Systems, Energy Analysis Department Environmental Energy Technologies Division Lawrence Berkeley National Laboratory Berkeley, CA 94720, US.

[7] Sustainable Energy Authority of Ireland (seai), Best Practice Guide-PV, Ireland.

[8] https://en.wikipedia.org/wiki/Feed-in tariff

[9] http://solargis.info/doc/solar-and-pv-data

[10] http://www.soda-pro.com

[11] http://www.indexmundi.com/france/central bank discount rate.html

[12] http://www.insee.fr/en/themes/series-longues.asp?indicateur=inflation

[13] http://www.lexology.com/library/detail.aspx?g=d059337e-c64a-40ab-b0117ece4ec8b741

[14] http://www.french-property.com/guides/france/utilities/electricity/tariff/

[15] https://www.frenchentree.com/living-in-france/utilities/electricity-tariffs-in-france/

[16] https://www.edf.fr/sites/default/files/contrib/content/EDF2014 IndicateursPerfor mance va.pdf

[17] http://www.rte-france.com/en/eco2mix/eco2mix-co2-en

[18] https://www.ipcc.ch/pdf/special-reports/sroc/Tables/t0305.pdf 